\title{
Smerteevaluering ved demens
}

\begin{abstract}
Sammendrag
Bakgrunn. Pasienter med demens er ofte ikke i stand til å uttrykke smerte pga. redusert hukommelse og språkbeherskelse. Det kan medføre underdiagnostisering og mangelfull smertebehandling. Artikkelen er et sammendrag av en avhandling, som beskriver utvikling og testing av et nytt evalueringsinstrument for smerte: Mobilisation-Observation-Behaviour-IntensityDementia (MOBID-2) smerteskala.
\end{abstract}

Materiale og metode. Totalt 284 sykehjemspasienter med demens av ulik grad og forskjellige typer, med og uten smerte ble inkludert for å registrere smerteatferd og tolket smerteintensitet ved gjentatte videoopptak under morgenstell, og ved klinisk unders $\varnothing$ kelse. Metodetesting av instrumentet inkluderte vurdering av reliabilitet, validitet og klinisk nytte for pleiepersonalet.

Resultater. Ved MOBID-2 smerteskala gir observasjon av smerteatferd under standardiserte, ledede bevegelser et godt grunnlag for reliabel og valid estimering av smerteintensitet relatert til muskel- og skjelettsystemet. Smerter som ikke relateres til muskel- og skjelettsystemet forekommer hyppig, men er vanskeligere å vurdere. Pasienter med alvorlig demens og kombinert Alzheimers demens og vaskulær demens er mer utsatt for ubehandlet smerte enn pasienter uten demens.

Fortolkning. MOBID-2 smerteskala kan være til hjelp for å sikre kompetent smertebehandling og bør være tilgjengelig på alle norske sykehjem. Det er stort behov for tverrfaglig tilnærming og implementering. Sykehjemsleger må revurdere pleiepersonalets observasjoner, gjennomføre supplerende undersøkelser og finne balansen mellom effekt og bivirkning av smertebehandling.

Basert på ph.d.-avhandling ved Institutt for samfunnsmedisinske fag, Universitetet i Bergen, 2008 (1)

\section{Bettina Sandgathe Husebø}

bettina.husebo@isf.uib.no

Institutt for samfunnsmedisinske fag

Universitetet i Bergen

5020 Bergen

Smerter, ofte sammensatte, forekommer hyppig hos pasienter med demens. Studier viser at $60-80 \%$ av sykehjemspasienter har smerter (2). Særlig de med langkommet demens er ikke i stand til å uttrykke smerte pga. redusert hukommelse, svekket språkbeherskelse og manglende refleksjonsevne (3). Sykehjemspasienter med demens får i mindre grad smertestillende behandling, både med hensyn til mengde og styrke av analgetika, enn kognitivt friske pasienter med antatt samme smertebelastning (4). Årsakene kan være mange, som vansker med å rapportere smerte og angi behandlingseffekt og eventuelle bivirkninger av analgetika.

70000 mennesker i Norge antas å ha en demenssykdom, og 10000 nye tilfeller forventes hvert år (5). Diagnosen demens er hovedårsak til innleggelse i sykehjem. En stor andel av Norges 41000 sykehjemspasienter har alvorlig demens. Den epidemiologiske utviklingen tilsier at demens er den sykdommen på verdensbasis som kommer til å øke mest, med forventet prevalens på $4 \%$ av befolkningen innen 2040 (6).

Hos klare og orienterte pasienter er smertevurdering, basert på selvrapportering, en opplagt forutsetning for vellykket smertebehandling (7). Siden selvrapportering ikke er mulig hos pasienter med alvorlig demens, er de avhengige av at pleiepersonale og andre omsorgspersoner har evne til å tolke verbale og ikke-verbale tegn som uttrykk for smerte, og at dette følges opp med tiltak for videre utredning og behandling (8). I de siste årene er flere observasjonsskjemaer for smerteatferd testet og utviklet, men i oversiktsartikler konkluderes det med at disse instrumentene har begrenset klinisk anvendbarhet ved alvorlig demens (3).

Mobilisation-Observation-Behaviour-Intensity-Dementia (MOBID-2) smerteskala er et nytt evalueringsinstrument for å kartlegge smerte hos pasienter med demens (fig 1). Instrumentet ble utviklet og testet i doktorgradsprosjektet «Assessment of Pain in Patients with Dementia» ved Universitetet i Bergen (1). Artikkelen er et sammendrag av avhandlingen og presenterer MOBID-2 smerteskala i norsk versjon for praktisk bruk i eldreomsorgen.
MOBID-2 er tilpasset pasientens hverdagssituasjon i sykehjem med vekt på pleiepersonalets observasjon av smerteatferd relatert til:

- Muskulatur, ledd og skjelett, under standardisert aktiv mobilisering

- Smerteatferd relatert til indre organer, hode og hud

Instrumentet ble testet med henblikk på reliabilitet og validitet $(9-11)$ og brukt $i$ en større sykehjemsstudie hos pasienter med ulike demenstyper og demensgrader, samt ulik bruk av analgetika (12).

\section{Materiale og metode}

MOBID-2 smerteskala

Prosjektet ble gjennomført i perioden 2004-08 og startet med utvikling av MOBID smerteskala (senere kalt MOBID-2 del 1), som registrerer smerteatferd og smerteintensitet ved fem vanlige mobiliseringer av pasienten: Pasienten ledes til å: 1) åpne begge hender, 2) strekke armene mot hodet, 3) bøye og strekke ankler, knær og hofte, 4) snu seg i sengen, 5) sette seg opp på sengekanten (9).

En pleieperson vurderer fortløpende pasientens respons, og etter hver bevegelse krysses det av for smerterelatert atferd som: Lyder («Au!» stønner, ynker seg, gisper, skriker), ansiktsuttrykk (lager grimaser, rynker pannen, strammer munnen, lukker øynene), samt avvergereaksjon (stivner, beskytter seg, skyver fra seg, holder pusten, krymper seg). Mobiliseringen avsluttes umiddelbart dersom man observerer atferd som kan være forbundet med smerte. Atferden tolkes deretter ut fra en $0-10$ punkts skala, der 0 er ingen smerte og 10 er verst

\section{Hovedbudskap}

- Alvorlig demente pasienter kan ikke formidle at de føler smerte pga. redusert hukommelse og språkbeherskelse

- Det fører til underdiagnostisering og mangelfull smertebehandling

- MOBID-2 smerteskala viser tilfredsstillende reliabilitet, validitet og klinisk anvendbarhet for smertevurdering

- Leger har ansvar for oppfølging av smertevurdering, smertebehandling og effektvurdering hos sykehjemspasienter 
tenkelige smerte (numerical rating scale, NRS).

Ved MOBID-2 smerteskala del 2 inkluderer instrumentet også smerteatferd antatt relatert til 6) hode, munn og hals, 7) bryst, lunge og hjerte, 8) øvre del av mage, 9) bekken, nedre del av mage, 10) hud, infeksjon, sår (11). En kroppsskisse ble inkludert for å øke personalets oppmerksomhet. Her oppfordres observatøren til å lokalisere observert smerteatferd på tegningen, samt til å angi smerteintensitet på smerteintensitetsskalaen, basert på observert smerteatferd eller ytret smerte hos pasienten i løpet av den siste uken. Når alle elementer, 1-10, er skåret, gis avslutningsvis en helhetlig vurdering av pasientens smerte, igjen på smerteintensitetsskalaen.

Før MOBID-2 smerteskala tas i bruk, anbefales det å gjennomføre et standardisert opplæringsprogram for pleiepersonalet, med søkelys på ulike diagnoser og stadier av demens, smerte relatert til muskel- og skjelettsystemet, indre organer, hud og hode, smerteatferd og bruk av smerteintensitetsskala og smertetegning.

\section{Utvikling}

MOBID-2 ble utviklet av et team med erfaring fra omsorg og behandling av pasienter med demens og smertebehandling, og kunnskap om testing av spørreskjemaer. Basert på egne kliniske observasjoner og systematisk søk i relevante databaser ble de fem bevegelsesvariantene utarbeidet, samt adjektiver relatert til smerteatferd, og en prosess for tolking av smerteintensitet. I utgangspunktet ble instrumentet utviklet på norsk. For internasjonal publisering av resultatene ble instrumentet oversatt til engelsk.

\section{Validering}

I en omfattende valideringsprosess ble MOBID-2 smerteskala testet med tanke på intratester, intertester $(9,10)$ og test-retestreliabilitet (11), begrepsvaliditet (construct validity) $(9,11)$, samtidig validitet (concurrent validity) (11) og innholdsvaliditet (content validity) (12)

Validering ble gjort med utgangspunkt i tre ulike pasientgrupper. I den første gruppen ble 26 pasienter med alvorlig demens og kronisk smerte videofilmet, mens pasientens primærkontakt, som hadde hatt ansvar gjennom de siste fire uker, ledet pasienten gjennom MOBID-2 smerteskala del 1 under morgenstell $(9,10)$. Den andre gruppen besto av 77 pasienter med alvorlig demens, med og uten kronisk smerte, som ble vurdert av pleiepersonalet med MOBID-2 (del 1 og 2) (11). Hver pasient ble samtidig og uavhengig undersøkt av to pleiepersoner med kjennskap til pasienten. Et tilfeldig utvalg pasienter gjentok undersøkelsen neste dag. Pasientansvarlige leger vurderte pasientens smertediagnoser, -lokalisasjon, -medikasjon og -intensitet. Den tredje gruppen besto av 181 langtidspasienter $i$ et sykehjem, med

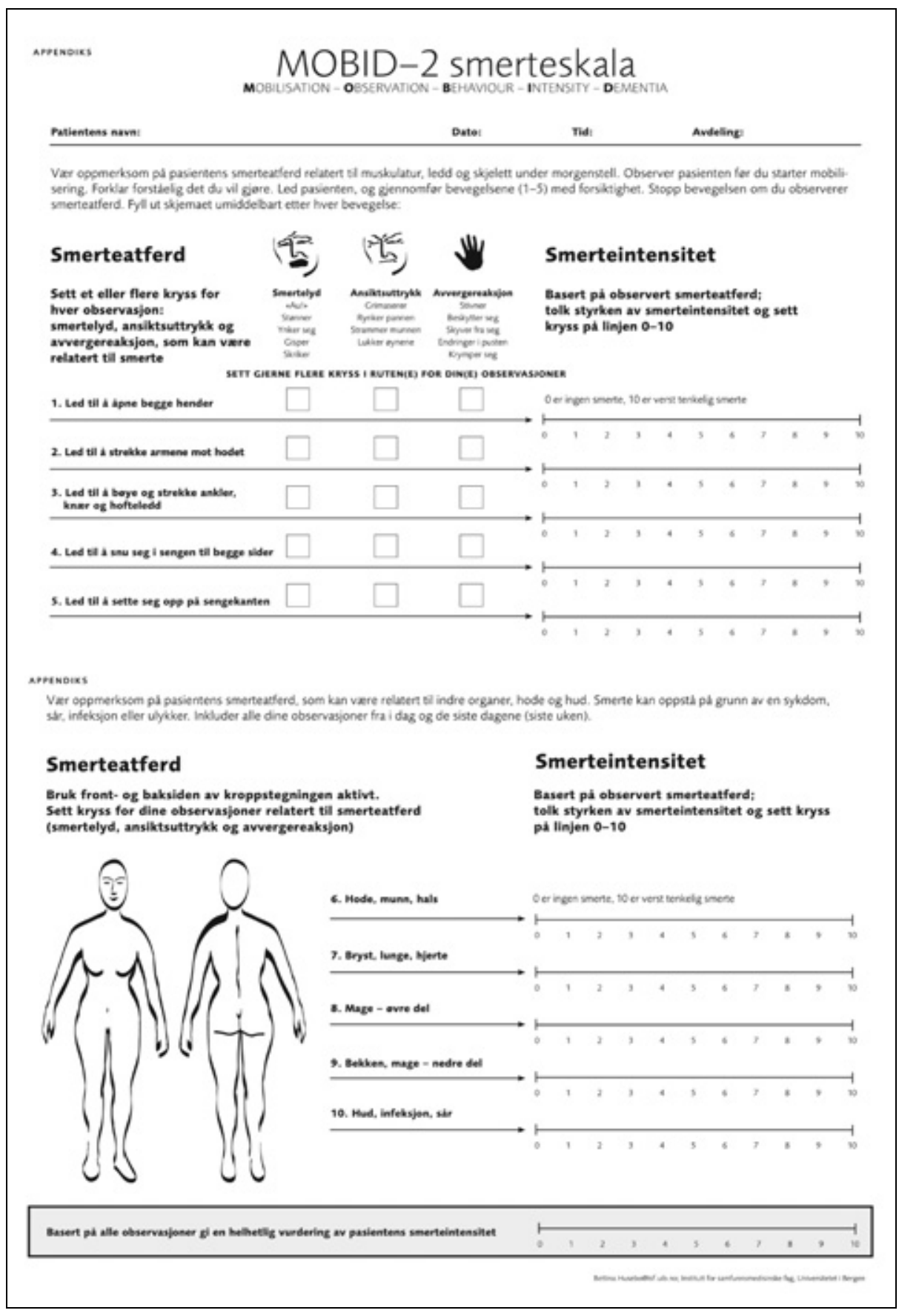

Figur 1 Smerteskalaen MOBID-2

demens av ulik grad og type, med og uten smerte (12). Pasientene ble vurdert av pleiere ved MOBID-2 smerteskala, og leger gjennomførte kliniske undersøkelser.

For å undersøke samtidig validitet (concurrent validity) ble MOBID-2 også vurdert med henblikk på korrelasjon mellom smerte vurdert av pleiepersonell/pårørende (proxy) og selvrapportert smerte hos pasienter uten demens (gullstandard) (Amundsen S, særoppgave, Det medisinske fakultet, Universitetet i Bergen, 2008).

\section{Resultater}

Studiene viser at MOBID-2 smerteskala kan gi reliable og valide skårer for smerteintensitet hos pasienter med demens. Analysene ble gjennomført under forutsetning av at personer som brukte instrumentet, hadde kjennskap til pasienten og hadde fått systematisk innføring i bruk av instrumentet. Observasjon av smerteatferd som respons på standardiserte bevegelser viste seg å være et godt grunnlag for å anslå smerteintensitet relatert til muskel- og skjelettsystemet. Når hele MOBID-2 smerteskala ble brukt ved sykesengen, hadde $80 \%$ av alle pasienter $(n=77)$ en MOBID-2-skår > 0 og 64 \% skåret $\geq 3$. Smerte fra muskel- og skjelettsystemet var dominerende $(58 \%)$ sammenliknet med smerte som ikke kunne relateres til muskel- og skjelettsystemet (42\%). Smerter som ikke relateres til muskulatur eller skjelett forekommer hyppig, men er vanskelige 
å vurdere. Analysen av sykehjemspasienter $(\mathrm{n}=181)$ med ulike grader og typer av demens viste at pasienter med alvorlig demens hadde like høy smerteintensitet som pasienter med mild og moderat demens, og pasienter uten demens. Pasienter med kombinasjon av Alzheimers demens og vaskulær demens hadde høyere smerteintensitet enn pasienter med kun Alzheimers demens eller uten demens. Det antas at sykehjemspasienter med sammensatte lidelser og tallrike ICD-diagnoser er underbehandlet for smerte, særlig de med alvorlig demens og kombinasjon av Alzheimers demens og vaskulær demens.

\section{Diskusjon}

MOBID-2 smerteskala er utviklet for å sikre de dementes behov for kompetent smertevurdering og behandling. Deres sykdomsutvikling fratar oss den viktigste metoden til evaluering av smerte: anamnese og sykehistorie fortalt av pasienten selv (13). Hos pasienter med demens og kognitiv svikt vil observasjon av atferd, sykehistorie fortalt av andre, kroppsundersøkelse og kartlegging av smerterelaterte diagnoser gi viktig informasjon om mulige smerteplager. Pleiepersonalet som kjenner pasienten fra det daglige stell, har de beste forutsetninger for å vurdere pasientens atferd med henblikk på smerteproblemer.

Personalet som deltok i avhandlingens datainnsamling ble tilbudt et opplæringsprogram om smertefysiologi, -vurdering og -behandling. Programmet er ikke ennå testet med henblikk på opplæringseffekt og er foreløpig ikke et standardisert undervisningstilbud. «Smertefritt Sykehjem» er et planlagt forskningsprosjekt for å utvikle og implementere et nettbasert opplæringsprogram om smertevurdering og -behandling, som skal være tilgjengelig for alle helsearbeidere i norske sykehjem - uavhengig geografi, tid og sted. Resultatparametere for personalets kunnskap og holdinger, og forbedringer av smertebehandling vil bli utviklet for å belyse den systematiske effekten av formidling og kompetanseheving. Studien vil også evaluere hvorvidt det er realistisk å implementere MOBID-2 smerteskala som et standard verktøy i norske sykehjem.

Legens rolle som teamleder for å utvikle slik kompetanse er helt sentral. Legen må revurdere pleiepersonalets observasjon, gjennomføre supplerende kliniske undersøkelser og anbefale terapi. Optimalt sett bør vurderingen og behandlingen baseres på tverrfaglig teamarbeid som også inkluderer pleiepersonalet, fysioterapeut, ergoterapeut og miljøterapeut. Slike forutsetninger er sjelden til stede på sykehjemmet, og legens tilstedeværelse er oftest begrenset til noen timer eller en dag i uken.

Det er en utfordring å finne balansen mellom effekt og bivirkninger av smertebehandling hos pasienter med kognitiv svikt. Pasientenes mangelfulle evne til selvrapportering gjelder ikke kun smerte, men fører også til manglende tilbakemelding om behandlingseffekt og bivirkninger av analgetikaterapi. Pasienter med sammensatte lidelser er mer utsatt for bivirkninger og interaksjoner. Det er et stort behov for praktiske anbefalinger innenfor smertebehandling hos denne sårbare gruppen.

Forskning som omhandler pasienter med alvorlig demens er metodisk og etisk utfordrende pga. pasientens manglende evne til å gi informert samtykke. I vårt prosjekt har det ikke vært mulig å innhente informert samtykke basert på pasientens forståelse. Tilstanden av demens og dermed grunnlaget for prosjektet er at pasienter ikke er i stand til å rapportere smerte.

Det er uheldig om mangelfull samtykkekompetanse medfører at forskning ikke kan gjennomføres, når det må antas å medføre fordeler for deltakerne selv og den pasientgruppen de tilhører. Samtidig behøver pasientene beskyttelse mot forskning med uklare mål, problemstillinger og metoder. Det er i dag nasjonale og internasjonale variasjoner med hensyn til godkjenning av slike prosjekter (14). I vårt prosjekt fikk vi primært avslag fra Helsedirektoratet til bruk av video for å validere MOBID-2 smerteskala. Etter at vi innhentet en juridisk betenkning som fastslo at videofilming i demensforskning ikke er i strid med nasjonale og internasjonale retningslinjer, fikk vi den nødvendige godkjenning.

Det gjenstår i den videre valideringsprosess å sammenlikne smerteregistrering ved MOBID-2 med andre instrumenter (samtidig validitet). MOBID-2 vil også bli testet på responsivitet for å undersøke om instrumentet fanger opp forandringer i smerteintensitet etter at smertebehandlingen ble satt i gang.

Det vil alltid være vanskelig å skille mellom atferd relatert til demens og atferd relatert til smerte. Hovedårsak til dette er at det ikke finnes typiske utrykk for smerte blant de emosjonelle reaksjoner i ansiktet (15). Spesielt utrykket for angst er hyppig blant pasienter med demens, og mange har psykiatriske lidelser. Antakelig medfører smerter økende atferdsproblemer i denne gruppen, og i et aktuelt postdoktorsprosjekt vil vi vurdere hvorvidt individuell smertebehandling har en positiv effekt på agitasjon.

Evaluering og behandling av smerte ved kognitiv svikt er helt avhengig av stabilt, kompetent, motivert personale med tverrfaglig bakgrunn. MOBID-2 smerteskala fremstår som et valid og reliabelt evalueringsinstrument tilpasset hverdagen innenfor norsk eldreomsorg.

Jeg takker mine veiledere Anne Elisabeth Ljung gren, Rolf Moe-Nilssen, Liv Inger Strand, og forskergruppen Stein Husebø, Lynn Snow og Dag Årsland. Studien er støttet av Helse og rehabilitering, og Kavli's forskningssenter for aldring og demens.
Oppgitte interessekonflikter: Ingen

Litteratur

1. Husebo BS. Assessment of pain in patients with dementia. Ph.d.-avhandling. Bergen: Institutt for samfunnsmedisinske fag, Universitetet i Bergen, 2008

2. Ferrell BA, Ferrell BR, Rivera L. Pain in cognitively impaired nursing home patients. J Pain Symptom Manage 1995; 10: $591-8$.

3. Hadjistavropoulos T. Herr K, Turk DC et al. An interdisciplinary expert consensus statement on assessment of pain in older persons. Clin J Pain 2007; 23 (suppl): 1-43

4. Nygaard HA, Jarland M. Are nursing home patients with dementia diagnosis at increased risk for inadequate pain treatment? Int J Geriatr Psychiatr 2005; 20: 730-7.

5. Selbaek G, Kirkevold O, Engedal K. The prevalence of psychiatric symptoms and behavioural disturbances and the use of psychotropic drugs in Norwegian nursing homes. Int J Geriatr Psychiatry 2007 22: $843-9$

6. Ferri CP. Prince $M$, Brayne $C$ et al. Global prevalence of dementia: a Delphi consensus study. Lancet 2005; 366: 2112-7.

7. Turk DC, Okifuji A. Assessment of patients' reporting of pain: an integrated perspective. Lancet 1999; 353: $1784-8$

8. American Geriatrics Society Panel on Chronic Pain in Older Persons. The management of chronic pain in older persons. J Am Geriatr Soc 1998; 46: 635-51.

9. Husebo BS, Strand LI, Moe-Nilssen R et al. Mobilization-Observation-Behavior-Intensity-Dementia Pain Scale (MOBID): development and validation of a nurse-administered pain assessment tool for use in dementia. J Pain Symptom Manage 2007: 34: 67-80.

10. Husebo BS, Strand LI, Moe-Nilssen R et al. Pain behaviour and pain intensity in older persons with severe dementia: reliability of the MOBID Pain Scale by video uptake. Scand J Caring Sci 2009; 23: $180-9$

11. Husebo BS, Strand LI, Moe-Nilssen R et al. Pain in older persons with severe dementia. Psychometric properties of the Mobilization-Observation-Behaviour-Intensity-Dementia (MOBID-2) Pain Scale in a clinical setting. Scand J Caring Sci 2009; akseptert for publisering.

12. Husebo BS, Strand LI, Moe-Nilssen R et al. Who suffers most? Dementia and pain in nursing home patients: a cross-sectional study. J Am Med Dir Assoc 2008: 9: 427-33.

13. Tait RC, Chibriall JT. Under-treatment of pain in dementia: assessment is key. J Am Med Dir Assoc 2008; 9: 372-4.

14. Rikkert $M G$, Lauque $S$, Frolich $L$ et al. The practice of obtaining approval from medical research ethics committees: a comparison within 12 European countries for a descriptive study on acetylcholinesterase inhibitors in Alzheimer's dementia. Eur J Neurology 2005; 12: 212-7.

15. Ekman P. Facial expression and emotion. Am Psychologist 1993; 48: 384-92.

Manuskriptet ble mottatt 12.12. 2008 og godkjent 5.8. 2009. Medisinsk redaktør Odd Terje Brustugun 